REVISTA ANDALUZA DE ANTROPOLOGÍA.

NÚMERO 5: APORTACIONES Y POTENCIALIDADES DE LA ANTROPOLOGÍA DE LA SALUD.

SEPTIEMBRE DE 2013

ISSN 2174-6796

[pp. 91-104]

http://dx.doi.org/10.12795/RAA.2013.i05.05

Fecha de Recepción: 21-06-2013

Fecha de Aceptación: 26-08-2013

\title{
EL CUERPO (RE) PRODUCTIVO. INTERÉS ECONÓMICO Y ALTRUISMO SOCIAL EN LAS EXPERIENCIAS DE UN GRUPO DE MUJERES DONANTES DE ÓVULOS
}

\author{
Gemma Orobitg \\ Departamento de Antropología Cultural y de Historia de América y África. Universidad \\ de Barcelona.
}

Joan Bestard

Departamento de Antropología Cultural y de Historia de América y África. Universidad de Barcelona.

\section{Carles Salazar}

Departamento de Historia del Arte e Historia Social. Universidad de Lleida.

\section{Resumen.}

En nuestra investigación sobre un grupo de donantes de óvulos en una clínica privada de Barcelona, nos dimos cuenta que la donación de óvulos no puede ser abordada como un acto con un significado único, sino más bien como un proceso en el que diferentes y a veces contradictorios significados adquieren relevancia. En un primer momento de su proceso como donantes, la mayoría de estas mujeres destaca el carácter altruista de su acción. En sus testimonios, insisten también en el tipo de maternidad simbólica en el que están participando para ayudar a otras mujeres a ser madres reales (legales). Poco a poco, sin embargo, los malestares físicos que el proceso de la donación de óvulos implica para las donantes (estimulación ovárica, cirugía, etc.) así como el mismo protocolo del proceso clínico, las hace más sensibles a la importancia económica de los pagos que 
reciben por la donación de sus óvulos. Desde el punto de vista de la clínica, la donación de óvulos es claramente un acto económico del que se obtiene un recurso necesario (y escaso). Desde el punto de vista de las donantes, la compensación económica les ayuda a "objetivar" la donación, impidiendo la creación de cualquier parentesco imaginario con los niños por nacer gracias a su donación (y con sus madres legales o receptoras de óvulos).

Palabras clave: reproducción asistida, donación de óvulos, altruismo, maternidad simbólica, compensación económica, género.

\section{Abstract.}

In our research among ova donors in a private clinic of Barcelona we noticed that ova donation could not be seen as a single act endowed with a unified meaning but rather as a process in which different, sometimes contradictory, meanings were prominent at different stages. Initially, most ova donors emphasized simultaneously the altruistic nature of their action and the sort of symbolic motherhood that they wished to achieve by helping other women to be real (legal) mothers. Gradually, however, the harsh discomforts that the process of ova donation entails for the donors (ova hyperstimulation, surgery, etc.) made them more sensitive to the economic significance of the payment they received. From the clinic's point of view, ova donation is clearly an economic act by which they obtain a necessary (and scarce) resource. From the donor's point of view, that payment helped them to 'objectify' their transaction by preventing them from creating any imaginary kinship with the children to be born thanks to their act (and their legal mothers or ova recipients).

Keywords: assisted reproduction, ova donation, altruism, symbolic motherhood, economic compensation, gender.

\section{INTRODUCCIÓN}

Este texto quiere aportar algunos datos etnográficos para dar sentido a una paradoja presente en las narraciones de las 25 mujeres que participaron en una investigación sobre las implicaciones sociales y culturales de la donación de óvulos. En sus testimonios, estas mujeres representaban la donación de óvulos como un acto altruista, al mismo tiempo que valoraban como necesaria la compensación económica que iban a recibir de la clínica en la que estaban realizando la donación. Desde la perspectiva de las biólogas de la clínica, en un estudio elaborado a partir de los resultados de la misma investigación, "esta contradicción demuestra la existencia de una cierta presión social para considerar la donación como un acto altruista cuando, en realidad, la cantidad económica de la compensación representa un incentivo importante para las donantes" (Pareja, 2003: 75). La etnografía, por su parte, nos ha llevado a interesarnos no tanto por resolver sino por 
analizar esta contradicción presente en los relatos de las donantes. En concreto, nuestro objetivo es elaborar una descripción etnográfica sobre la forma en cómo se introducen el interés económico y el sentimiento altruista en los relatos sobre la donación de óvulos como lenguajes simbólicos. Esta descripción mostrará la yuxtaposición de estos dos lenguajes, el económico y el moral, en las narraciones de las donantes. En realidad, se trata de lenguajes aparentemente contradictorio desde nuestras categorías analíticas que oponen interés y altruismo, sin embargo en las narraciones de las donantes, una y otra, adquieren mucho sentido en la explicación de la experiencia de la donación de óvulos. En los relatos de estas mujeres, el interés y el altruismo, son dos valores que ordenan las motivaciones de su acción como donantes (Daniel D. Hutto, 2008)

La yuxtaposición, en la experiencia de la donación de óvulos, del lenguaje económico y del moral se articula con unas determinadas representaciones del parentesco, del cuerpo, de las sustancias corporales y de los genes que justifican la donación de óvulos pero que, al mismo tiempo, la problematizan. Si, por un lado, donar óvulos se justifica como una posible solución al problema de la infertilidad; por otro lado, donar óvulos significa la cesión de una parte del propio cuerpo. Se donan substancias a través de las cuales se conceptualiza el parentesco. Las personas que participan de la experiencia de la donación elaboran una serie de reflexiones sobre las relaciones entre las representaciones del cuerpo y las ideas del parentesco y del género. Se trata de una relación compleja en la que ningún elemento define el sentido de los otros. Es, más bien, una "coreografía flexible" (Thomson, 2001) entre diferentes elementos que dan sentido a las donaciones y a las nuevas relaciones de parentesco hechas posibles a partir de ellas.

Esta perspectiva aportará nuevos elementos para el debate ético entorno a la compensación económica que reciben las donantes de gametos. Se trata, en particular, de unos planteamientos que nos permiten pensar el debate ético desde una perspectiva relacional: al considerar la donación de óvulos desde la experiencia de las donantes, la compensación económica que desde la perspectiva esencialista de las representaciones sociales del cuerpo, de las sustancias, de la filiación y del parentesco puede ser éticamente cuestionada, se configura como un lenguaje eficaz, aunque no el único, en el proceso de dar sentido a la experiencia individual de la donación. En otras palabras, pensar la donación incorporando la compensación económica como un aspecto necesario contribuye a hacerla "aceptable" y "posible".

Al mismo tiempo, estas experiencias individuales cuestionan y transforman las ideas contemporáneas sobre el parentesco y el cuerpo. En particular, en contextos como el de la donación de óvulos, la fragmentación de la experiencia corporal de la reproducción -donantes, personal sanitario y receptoras, por un lado y ovulación, fecundación y gestación, por otro lado-, que las directivas legales y los protocolos médicos consolidan, se traduce, entre otras cosas, en el surgimiento de una representación fragmentada del parentesco que abre la posibilidad de articular distintas combinaciones de relaciones 
como sustancias del parentesco (Bestard, 2003). Se configuran, de esta manera, nuevas representaciones del cuerpo y del parentesco que están en la base de la reformulación del debate ético sobre la reproducción asistida. En lo que insistimos es en la agencia e imaginación (Carsten, 20004) que las donantes despliegan al participar en nuevas formas de parentesco.

\section{EL CONTEXTO LEGAL DE LA DONACIÓN DE ÓVULOS EN ESPAÑA}

La donación de óvulos, según la ley de reproducción asistida de 1988, “ 1. [...] es un contrato gratuito, formal y secreto concertado entre el donante y el centro autorizado [...] 3. La donación nunca tendrá carácter lucrativo o comercial [...]” (Ley 35, 22 de Noviembre de 1988, capítulo III, artículo 5).

Sin embargo, la Comisión Nacional de Reproducción Humana Asistida, creada por un Real Decreto del 21 de marzo de 1997, órgano de consulta y de consejo permanente para la Administración y las instancias clínicas en el desarrollo de la Ley, aconseja, en su informe anual de 1998, que las donantes reciban una compensación económica controlada "por los gastos en que pueda haberse incurrido como consecuencia de la donación, así como de las molestias y trastornos producidos". La cantidad de esta compensación, insiste la Comisión Nacional, debe ser controlada para que no quede desvirtuado el carácter no lucrativo de la donación. Al mismo tiempo que en la regulación de la compensación económica se insiste, sin proporcionar más detalles, en que deberán fomentarse las campañas para la donación altruista.

Según este mismo informe de la Comisión, la compensación económica es necesaria para mantener los índices de la donación sin que se cree un "mercado oculto de gametos [...] cuya existencia se considera éticamente rechazable". Así mismo, se expone en este informe de la Comisión Nacional de Reproducción Humana Asistida de 1998, "hay también indicios de que, pese a las previsiones normativas y las recomendaciones existentes, la compensación puede ser en algunos casos el motivo fundamental de la donación" (Lacadena, 1999).

En este punto es interesante destacar que el documento de la Comisión Nacional de Reproducción Humana Asistida, en su propuesta para la retribución de la donación de gametos, reproduce la yuxtaposición entre el ideal del altruismo y la valoración de la compensación económica que expresan las donantes de óvulos cuando explican su experiencia de la donación.

\section{LOS RELATOS DE LAS DONANTES DE ÓVULOS}

Los testimonios que se presentan seguidamente fueron recogidos entre los años 2002 y 2003 en el momento en que estas mujeres estaban siguiendo un tratamiento para donar sus óvulos en el Centro de Medicina de la Reproducción del Instituto Universitario Dexeus de Barcelona. Los epígrafes que organizan los datos etnográficos que presentamos 
a continuación re-construyen la experiencia de la donación de óvulos poniendo especial énfasis en la compensación económica como un lenguaje simbólico del que se apropian las donantes de óvulos en su proceso de construcción del sentido del acto de donar esta parte de su cuerpo.

\section{"Es como si vendieras algo tuyo..."}

$\mathrm{Ana}^{1}$, una de las veinticinco mujeres donantes de óvulos que participaron en la investigación, contaba como un día su marido le comentó que había escuchado en la radio que se necesitaban donantes de óvulos y que daban una compensación económica. La idea, así en frío, no la convenció. Se puso a pensar. Le costaba tomar una decisión. Tenía la sensación de que era como vender algo suyo. Sus óvulos eran algo muy personal. De ahí habían salido sus hijos. Claro que su marido no lo veía así. Y es que, reflexionaba Ana, los hombres no viven igual este tema de la maternidad. No acababa de decidirse a donar sus óvulos y siguió pensando. Distintas ideas le vinieron a la mente que le llevaron finalmente a tomar la decisión ser donante de óvulos. Pensó que tanto ella, como su marido, como sus hijos ya eran donantes potenciales porque si les pasara alguna cosa y pudieran donar algo, lo harían. Una vez muerta, se dijo, aunque sonara frío, daba igual lo que hicieran con ella. ¡Mejor, si podía salvar una vida! Pensó también que la compensación económica por la donación de óvulos estaba bien, pero que tampoco era tanto dinero. No les iba solucionaba la vida. "No es el dinero [la motivación de la donación], insistía durante nuestra conversación, en el sentido de que no es una cosa [la compensación económica] que a ti te vaya a arreglar la vida. Bueno que no estás dando ahora [tus óvulos] y te va a solucionar la vida". La compensación económica la veía más bien como una ayuda para su familia. Le iba a permitir renovar el vestuario de sus hijos que buena falta les hacía y comprar alguna cosita para la casa.

\section{"Es como si fuera un trabajo..."}

Finalmente, explicaba Ana, había tomado la donación de óvulos como un trabajo por el que le estaban recompensando. Había acabado viendo la compensación económica como una manera de cubrir los gastos por los desplazamientos, por todas las molestias físicas que producía el tratamiento hormonal que se administra a las donantes para estimular la producción de óvulos y por toda la presión psicológica que sentía en esos días del tratamiento previos a la extracción quirúrgica de los óvulos.

En la misma línea describía su proceso Marta, una joven de 21 años que desde los 18 años había decidido que quería donar sus óvulos. Simplemente había visto en los muros de la Universidad, en su primer año de estudios, un anuncio en el que se solicitaban donantes de óvulos y de esperma. En ese momento pensó que sería bonito que una mujer pudiera

1. Los nombres que aparecen en el texto son ficticios 
tener un hijo gracias a ella. Decidió, en ese mismo instante, que iba a ser donante. Así empezó la narración de su experiencia. No había querido tomar pastillas anticonceptivas pensando que quizás le afectarían en el momento de la donación. Así pues, insistía, había decidido ser donante de óvulos cuando tenía 18 años. Y “... a los 18 años, explicaba Marta en nuestra conversación, era totalmente altruista... a los 18 años estás un poco... [silencio]". Ahora estaba donando porque seguía teniendo ganas de hacerlo, pero sobre todo por la compensación económica. Quizás mitad y mitad, se decía a si misma. Sus amigos le insistían en que se estaba "machacando" el cuerpo. Ella sentía, después de cada una de las inyecciones del tratamiento hormonal, que estaba teniendo emociones que no eran suyas, que estaban provocadas por el tratamiento. Quizás, se preguntaba, “en la clínica me están manipulando”. “En que sentido?” le preguntamos. "En el sentido, respondió, en que las mujeres que vienen a la clínica seguramente pagan mucho dinero para quedar preñadas con mis óvulos y a mi no me pagan lo que me corresponde en relación a lo que ellas pagarán". Sus amigos le criticaban que estaba entrando en el "sistema”. Tenían razón, se decía Marta en el momento de nuestra conversación. Claro que esto era algo que no había pensado antes, lo estaba pensando por primera vez durante el proceso de la donación.

\section{"Al principio lo hacía por altruismo pero después pensé que no tanto... si no me pagaran quizás no lo haría”.}

Con estas palabras continúa Marta su relato. En ellas, esta joven expresa claramente el proceso del que hablaba también Ana, en el primer testimonio presentado en este texto. Se trata de un proceso que aparece de forma recurrente en las narraciones de las donantes que participaron en nuestro proyecto: la compensación económica, si bien no es el principal motivo que las ha decidido a ser donantes, se convierte en una de las motivaciones principales de la donación de óvulos durante la experiencia clínicomédica de la donación. Para Marta, ceder un óvulo a una mujer que lo necesitara fue la primera motivación, explicaba, pero con el tiempo, la compensación económica se convirtió también en una razón de peso.

Igualmente, para otra de estas 25 mujeres, Pilar, donar sus óvulos era, en un principio, hacer feliz a otra mujer. Sin embargo, durante el tratamiento clínico para la donación empezó a dar importancia a la compensación económica. "Va muy bien. Es importante... a mi me paga el seguro del coche", dijo respondiendo a una de nuestras preguntas. "Además, añadió, pienso que tiene que ser más alta [la compensación económica] porque lo pasas mal. Tienes una regla fuerte, te duelen los pechos... a mi ni la regla ni los pechos nunca me habían hecho tanto daño". La verdad, insistía Pilar, es que "no te puedes poner a pensar en si donas o no una parte de tu cuerpo. Es mejor pensar que ayudas a una persona que no tiene hijos y encima a ti te pagan", comentó irónicamente.

Siguiendo su relato Pilar insistía, como lo hicieron otras donantes, en que para ella sería 
importante saber si realmente con sus óvulos alguien había podido tener un hijo. Sin embargo Pilar, como las demás donantes, sabía que esto era imposible.

Efectivamente, la donación de óvulos implica a tres sujetos en la relación: las donantes, las receptoras y la clínica. Las relaciones entre las donantes y las receptoras están prohibidas por la ley. La clínica, intermediaria necesaria en el acto de donar óvulos, tiene la responsabilidad de asegurar el anonimato de la donación. Se trata de un anonimato necesario para la mayoría de las donantes que, sin embargo, construyen, en sus narraciones de la experiencia de la donación, un imaginario intersubjetivo sobre las receptoras y los/as hijos/as resultado de la donación (Orobitg y Salazar, 2005).

Por su lado, las relaciones de las donantes con la clínica, las únicas que se permiten legalmente, las que estaban en juego en el momento en el que tuvieron lugar las conversaciones con las donantes que son la base de este trabajo, hacen surgir la idea de un cuerpo productivo. A través de la medicación y de la tecnología el cuerpo se convierte en un instrumento de producción. La experiencia de las donantes, por los protocolos biomédicos y por la mediación legal de la institución hospitalaria que asegura el anonimato de la donación, se restringe al proceso de la producción de los óvulos.

La experiencia de este cuerpo productivo durante el proceso clínico de la donación, en particular, los desplazamientos, las molestias en la organización de la vida cotidiana, el riesgo para la salud que pueden implicar el tratamiento hormonal y la intervención quirúrgica para la extracción de los óvulos así como los trastornos en el funcionamiento "normal" de cada cuerpo femenino convierten la donación en un esfuerzo/riesgo, en un trabajo - concretan algunas donantes - que justifica la compensación económica hasta hacerla necesaria. En realidad, la relación entre las donantes y la clínica está mediada por un contrato legal. La asociación con "un trabajo" convierte el cuerpo en un espacio de producción y extracción de óvulos. Esta es la idea que se les hace evidente a las donantes en el momento en el que inician su relación con la clínica.

Si la donación es un trabajo, y en este sentido se justifica la compensación económica, ¿los óvulos son pensados como un producto de mercado? La idea de un cuerpo productivo, y en particular el valor atribuido a partir de la compensación económica al proceso clínico de producción de los óvulos, desvaloriza la cosa donada, en este caso, la "desustantiviza" contribuyendo a hacer pensable la donación de óvulos en tanto que transacción económica.

Podríamos plantear la hipótesis de que si los gametos donados se desustantivizan es porque el contrato económico con la clínica consolida la fragmentación del proceso reproductivo y crea un contexto en el que la experiencia de la donación se circunscribe a la producción de óvulos; en otras palabras, queda restringida al proceso fisiológico de la ovulación estimulado por el tratamiento hormonal. En este contexto, la compensación económica ofrece una solución lógica a la experiencia de la donación, al mismo tiempo que una solución alternativa a la de la creación de una relación parentesco. 
Sin embargo, se trata de una desustantivización contextual, de un desplazamiento contextual de la sustancia del parentesco de los óvulos, los cromosomas y los genes a las relaciones emocionales y cotidianas que las madres receptoras tendrán con sus hijos (Orobitg y Salazar, 2005). Insistimos en el aspecto contextual de esta desustantivización porque no solo muchas de las donantes ya tenían hijos propios o planeaban tenerlos sino que este desplazamiento de la sustancia del parentesco no se hace sin dudas ni sin contradicciones por parte de las donantes.

El proceso a partir del cual se opera este desplazamiento de la sustancia del parentesco se expresa en un lenguaje económico. En particular, en un lenguaje del máximo aprovechamiento, que adquiere la carga de una especie de utilitarismo moral. Se trata de dar anónimamente un "excedente" para que pueda ser utilizado por otra mujer.

\section{"Dar una cosa que a mi me sobra..."}

Estas palabras pertenecen al relato de Marta, esta joven de 21 años que decidió ser donante a los 18 años. Se trata de una idea recurrente en las narraciones de estas 25 mujeres. “... Soy madre, -explica Sara, otra donante- se lo que es gastar una vida. Cada mes, cuando tengo la regla lo pierdo, no sirve para nada. De esta manera lo estoy donando y sirve para otra mujer...”.

Así se expresaba otra de las mujeres:

“...Yo no lo necesito, y lo voy a perder de todas maneras en cualquier regla y además los seguiré produciendo todos los meses [los óvulos]... a mi no me cambia nada y a la mujer que lo reciba le cambiará totalmente la vida”.

Para hacer aún más evidente de qué manera el lenguaje económico funciona en el desplazamiento de la sustancia del parentesco, será interesante completar los testimonios anteriores con el de esta donante:

“.. para mí no es un trastorno donar óvulos, ni voy a pensar más allá, porque mucha gente dice: "Ay, pues ahora irás por la calle y dirás: ¡Uy, ese se parece a mí!”. No, no sé, no tengo esa sensación. Tengo la sensación de dar una cosa que no la utilizo yo y la puede utilizar una persona y a lo mejor el día de mañana, pues yo tendré que utilizarlo de otra persona. No sé, es una sensación un poco como... de ayudar, pero tampoco... sí, un poco de ayudar y de... jolín, ya que lo puedes hacer ¿por qué no lo haces?”

Los testimonios que acabamos de presentar, completan siguiendo con un lenguaje económico, el proceso de desustantivización de la cosa donada. En este caso, los óvulos son pensados en términos de un excedente que se perdería si no se aprovechara con la donación de óvulos. Incluso, en el último de los testimonios presentados, los óvulos se presentan asociados a la idea de un objeto de circulación y de intercambio que pertenece a la donante. Las donantes no establecen una conexión concreta entre los gametos 
donados y una relación de filiación asociada al gameto. Es simplemente algo que ayuda y hace posible la filiación a otra mujer.

Es interesante notar cómo este lenguaje económico insiste en la ausencia del deseo/ voluntad de crear unas relaciones de parentesco directo pues se trata de óvulos que iban a "perderse". La idea central es que la mujer que dona no pensaba utilizarlos para crear una relación de parentesco. El lenguaje económico refuerza, en este sentido, un proceso que es necesario para hacer posible la donación: descartar la idea de la creación de vínculos del parentesco directos como resultado de la donación. Nótese que el lenguaje del parentesco muchas veces se opone el lenguaje económico. Es, pues, un buen instrumento para pensar la donación en términos genéricos de una ayuda anónima a otra mujer y no en términos de una sustancia biogenética que constituye una relación de filiación. En el caso de estas donantes estas relaciones no se crean porque no son deseadas, contrariamente a lo que sucede con las receptoras en quienes el deseo de tener hijos se convierte en la principal sustancia del parentesco.

Por ello, lo que emerge en las narraciones de las donantes, como indisociable de este lenguaje económico, es el lenguaje moral/emocional del deseo de ayudar a otra mujer. Retomemos el testimonio de Ana con el que iniciábamos la presentación de las narraciones de las donantes. En su relato, caracteriza ambos lenguajes a partir de identificaciones de género: el lenguaje económico y el lenguaje moral son asociados respectivamente a la experiencia masculina y a la experiencia femenina del proceso reproductivo. Los significados de la experiencia de la donación que se expresan a partir de este lenguaje económico se contradicen, según el testimonio de Ana que transcribimos a continuación, con su experiencia de la donación, se imponen a ella y crean un conflicto entre el lenguaje económico y la experiencia. Se trata de una contradicción entre el lenguaje económico y la experiencia que expresa esta mujer en términos de una experiencia de género.

Estas son las palabras de Ana: “...tú piensas que realmente es una parte tuya que irá a parar a otra persona, que de lo que nazca de ahí una parte es tuya. Y ellos [el marido y los hombres, en general] no lo ven así. O sea, ellos ven que tú ovulas y que si quieres tener un hijo te sirve para algo pero que si no, no. Que si vas a tener la menstruación, se va a morir $y$ lo vas a echar a perder". Pero ella, sigue el relato de Ana, no se imagina la vida sin sus hijos. En este sentido, lo importante para ella es dar la oportunidad a alguien que no puede tener hijos. Ella es muy consciente, insiste, de que está "donando una vida". Y esto, estima ella, tiene mucho valor.

Todas estas consideraciones son necesarias para completar el significado del concepto de altruismo en el contexto de la donación de óvulos. El término altruismo solo fue utilizado en algunas ocasiones por las mujeres entrevistadas. Sin embargo, se introduce como concepto en nuestra investigación a partir de la encuesta que elaboramos en colaboración con las biólogas de Centro de Medicina de la Reproducción y que rellenaban las mujeres al final de la conversación. A partir de sus comentarios, el altruismo, en el contexto de la 
experiencia de la donación de óvulos, se concreta en la narración de ayudar a quien no puede a tener hijos, donando, precisamente, algo que no se va a utilizar, que se echaría a perder si no se donara pero que es, al mismo tiempo, algo que tiene un gran valor. "...no hay dinero suficiente -decía otra de las donantes que reconocía también la utilidad de la compensación económica- para pagar lo que estás dando que es una parte de tu cuerpo".

\begin{abstract}
"Es una parte de mi pero no es un hijo mío..."
"Se puede parecer físicamente. Es lo más probable. Claro, lleva genes míos puede tener algo de mi personalidad... pero, no sé, yo tengo dos hijos y los he parido y uno es la noche y el otro es el día..."

"Los cromosomas son míos [...] físicamente será hijo mío, se parecerá a mi [...] pero mi hijo será el que yo para, el que me lo haga pasar mal, este será mi hijo. Mientras [no sea así] nada..."

“...no voy a tener yo el niño durante nueve meses. Lo único que hago es contribuir un poco en la cadena [... tampoco tengo que ver mucho porque solo pongo un poquito, los óvulos, luego la madre, y sobre todo los que crían a los hijos son los padres"[...] “... pienso que el niño que tenga esta mujer se puede parecer un poco a mi, en rasgos personales, rasgos físicos como yo. La idea me gusta... aunque seguramente se parecerá poco a causa de la educación..."
\end{abstract}

Invariablemente, en algún momento de sus testimonios, cada una de estas mujeres reconoce que está donando una parte de su cuerpo, en términos de "óvulos", "cromosomas" o "genes". Sin embargo, también aparece claramente en estos relatos que compartir óvulos, cromosomas o genes no crea una relación de filiación, pues se trata, y esta es una idea recurrente, de una relación incompleta. De nuevo el lenguaje económico contribuye al sentido de la donación, el hecho de que la donante pueda expresar su lugar en ella como el de un eslabón en la cadena productiva desvincula a la mujer de lo que dona. Las partes del cuerpo donadas son, de alguna manera, sustancias que pierden el aspecto concreto de la relación de parentesco y entran en el contexto abstracto de una donación anónima. Tal como expresan los testimonios que hemos trascrito como epígrafe, los óvulos donados se piensan como algo incompleto, como células que necesitan del esperma para completar el proceso de fecundación que junto con el proceso de gestación crean una parte de los lazos de parentesco, según aparece en las narraciones de las donantes. Se trata de unos lazos de parentesco, continuando con los testimonios de estas mujeres, que se completan con las relaciones cotidianas, afectivas y educativas, que las receptoras establecerán con los hijos/as resultado de la donación (Orobitg \& Salazar, 2005). Las donantes no están implicadas en ninguna de estas relaciones, renuncian a ellas cuando firman el contrato de donación. 
Sin embargo, compartir óvulos, cromosomas o genes lleva a pensar invariablemente en un parecido físico o de temperamento que no completa la idea de una relación de parentesco, aunque permite imaginarla. En ciertos momentos de sus narraciones, algunas de estas mujeres pudieron pensar la donación de óvulos como una forma alternativa de maternidad a través de otra mujer o de otra pareja. Así mismo, en determinados momentos de las narraciones, las células, los genes y los cromosomas compartidos a partir de la donación eran las sustancias alrededor de la cuales las donantes organizaban este imaginario intersubjetivo sobre las receptoras y sobre los hijos/as resultado de la donación (Orobitg y Salazar, 2005). Sin embargo, ninguna de estas narraciones implica aceptar que el resultado de la donación sea una relación de parentesco, es la posibilidad de ayudar a la esperanza de otra mujer

La compensación económica, y el lenguaje económico que emerge de ella, la obligación legal del anonimato y el mismo tratamiento médico (de)limitan la experiencia de las donantes al proceso corporal de la ovulación cuyo resultado final es la producción de los óvulos. En este sentido, es interesante notar como la exigencia de establecer unos límites al uso de las técnicas de reproducción asistida, exigencia que aparece de forma recurrente en las narraciones de las experiencias de las mujeres y de los hombres implicados en un tratamiento de fecundación in vitro, desaparece de las narraciones de las donantes (Salazar y Orobitg, 2011). En las narraciones de las donantes únicamente aparecen unas titubeantes demandas de desplazar los límites de la donación cuando expresan su interés, no tanto por eliminar el anonimato, sino por conocer cuáles han sido los resultados de su donación. Y es que, volviendo a la idea central de este texto, la experiencia de las donantes está ya limitada, biomédica y legalmente, a la de un cuerpo productivo. La compensación económica viene a reforzar esta idea. Las donantes incorporan, hemos podido ver a través de los relatos presentados, esta representación a través del lenguaje simbólico de la economía.

La representación del cuerpo de las donantes como un cuerpo productivo, y en este sentido limitado a las relaciones de producción, es la que surge y se propone desde las instituciones legales, bioéticas y clínicas (Casado \& Egozcue, 2001). Las mujeres por su parte describen, como ya hemos podido constatar, un proceso en el que la valoración de la compensación económica por la donación se da únicamente cuando se inicia el tratamiento en la clínica. En pocos casos, según la narración de estas mujeres, la compensación económica ha sido el motor único de la donación y en todos los casos la referencia a la solidaridad con quien no puede tener hijos aparece como una cuestión central. En realidad, las donantes hacen suyo este lenguaje económico y lo usan creativamente para dar sentido a su experiencia y, sobre todo, para hacerla pensable y posible.

“...Te dicen: “¿Cuánto dinero te dan?", y dije yo: "Ciento veinticinco [125.000 pesetas]", y hay gente que dice: "Pues qué poco, jolín, que estás dando óvulos", y 
otra gente pues: "Ay qué bien, pues mira, pues voy a ser yo donante". Hay gente que solo mira el dinero, otros que ven muy poco... hay para todo tipo."

Testimonios como este, o el último testimonio de Ana en el que identificaba dos niveles de la experiencia asociados a dos lenguajes simbólicos, el económico y el moral, nos muestran como, desde la perspectiva de las donantes, se produce una representación que se centra, no en un cuerpo productivo de un excedente que no crea otra relación que la de producción, sino en un cuerpo/persona mediador en la creación de las relaciones de parentesco a través del deseo de ayudar a otra mujer a ser madre. Una y otra representación se yuxtaponen en los relatos de las donantes en el sentido en que, según sus narraciones, una no puede funcionar sin la otra.

En realidad una y otra representación completan las dos relaciones en las que están implicadas estas mujeres en el proceso de la donación: las relaciones con la clínica y las relaciones con las receptoras. Una y otra completa, por distintas vías, el desplazamiento de la sustancia del parentesco, operación necesaria, como hemos podido constatar en las narraciones de las donantes, para hacer posible la donación. Sin embargo una y otra representación presentan, como muestra el epígrafe de este apartado, dos formas de significar/valorar lo que se dona. Por un lado, los óvulos son el resultado de un proceso productivo en el que se gestiona un excedente y que, en tanto que excedente, tienen un valor limitado. Y por otro lado, los óvulos son una parte del cuerpo que reproduce algo de la donante y, por esta razón, tiene un valor incalculable.

"Si yo estuviera en esta situación (necesitar óvulos) me gustaría recibir una donación. ¿Pagar por los óvulos! En la clínica te dan un poco de dinero por la donación pero cuando las mujeres lo necesitan! Es horrible! Tener que pagar tanto dinero (la receptora) mientras a ti, la donante te dan algo pero no es mucho en relación a lo que estás haciendo..."

La conciencia de la diferencia de clase socioeconómica entre donantes y receptoras es un aspecto que aparece invariablemente en todos los testimonios de las donantes: las mujeres receptoras pueden pagar un dinero para ser madres del que ellas no disponen, aún más, donando óvulos obtendrán un dinero que necesitan para cuestiones familiares cotidianas. Es un dinero que va a gastarse de una forma muy concreta, cubriendo una necesidad familiar. No es un dinero que se diluya en un abstracto valor de cambio. Sin embargo, los aspectos relativos a la solidaridad de género diluyen lo que podría constituir una crítica social. La relación con la mujer que recibirá la donación y con los niños que nacerán de esta donación son pensados en términos también de un beneficio para la donante y su entorno familiar. Para quienes piensan que la donación implica algún tipo de responsabilidad con los niños que nacerán de ella, el hecho de que la familia receptora tenga una buena situación económica es la garantía de un bienestar y de buenas posibilidades económicas y de ascenso social para estos niños a cuyo nacimiento habrán contribuido. Para las donantes que, sin considerar las relaciones de parentesco, toman en 
consideración vínculos genético, la existencia de estos niños nacidos de la donación de sus óvulos asegura, para el futuro, mayores posibilidades de compatibilidad en caso de que sus hijos sufran algún tipo de enfermedad.

El lenguaje económico tan central para construir el sentido de la donación en la narración de las donantes encuentra su justificación en el hecho mismo de estas diferencias socioeconómicas que la donación de óvulos hace evidentes. Parece que es más "horrible" hacer pagar mucho dinero por recibir unos óvulos que recibir una suma de dinero no demasiado elevada por donarlos. Además los beneficios de la donación, económicos y médicos, inmediatos y en el futuro, son imaginados como un esfuerzo que revierte en un beneficio para la familia de la donante o en su proyecto social.

\section{CONCLUSIONES}

El lenguaje económico se introduce en la construcción del relato de la experiencia de las donantes planteando, en un primer momento, dilemas éticos. Supone pensar la donación de una parte del cuerpo en términos económicos. Sin embargo, durante el proceso clínico de la donación, este lenguaje económico adquiere otra significación. Se produce una valorización de la compensación económica por la donación yuxtapuesta al lenguaje moral del altruismo. De esta manera, se da solución, desde el punto de vista de las donantes, al dilema ético y se construye el sentido de la donación. Igualmente se opera un el desplazamiento de las relaciones de parentesco centradas en la receptora, en particular, entre la receptora de estos óvulos y los hijos/as resultado de la donación. El lenguaje económico es pues un elemento en este proceso de desplazamiento hacia la receptora y la condición para constituir el sentimiento de donación en términos de un altruismo anónimo dirigido a otras mujeres. 


\section{REFERENCIAS BIBLIOGRÁFICAS}

Bestard, Joan (2003) "Cultura i Nova genètica. Sobre algunes connexions entre Cultura i Naturalesa". Quaderns de l'Institut Català d'Antropologia, no 19: 97-110

Bestard, Joan (2009) Knowing and relating: kinship, assisted reproduction technologies and the new genetics. En J. Edwards and C. Salazar (eds.) European kinship in the age of biotechnology. Oxford: Berghahn Books.

Carsten, Janet (2004) After Kinship. CUP.

Casado, My Egozcue, J. (coord.) (2001) Documento sobre donación de ovocitos. Barcelona: Observatori de Bioètica i Dret, Universitat de Barcelona.

Lacadena, Juan Ramón (1999) "Comisión nacional de reproducción humana asistida, informe anual, 1998 (Hecho público el 3 de Marzo de 1999) Resumen general”. Genética y Bioética, Ministerio de Educación y Ciencia. [http://www.cnice.mecd.es/tematicas/ genetica/index.html]

Hutto, Daniel D. (2008) Folk Psychological Narratives. The Sociocultural Basis of Understanding Reasons. A Bradford Book. Cambridge, Massachussets. London, England: The MIT Press.

Konrad, Monica (1998) "Ova donation and Symbols of Substances: Some variations of the Theme of Sex, Gender and the Partible Person," JRAI 4(4): 643-67.

Orobitg, Gemma y Salazar, Carles (2005) 'The gift of motherhood: Egg donation in a Barcelona infertility clinic', Ethnos, 70(1): 31- 52

Pareja, J.; Boada, M.; Orobitg, G.; y Barri, P.N. (2003) "Implicacions Socioculturals de la donació d'oòcits: el punt de vista de la donant". En Biologia de la Reproducció. 8es Jornades de la Secció de Biología de la Reproducció: Societat Catalana de Biología, vol. 8: 73-79.

Salazar, Carles y Orobitg, Gemma (2011) "The making of an imagined community. Press as a mediator in ethnographic research into Assisted Reproductive Technologies (ART)". Ethnography, 13(2): 236-255.

Thompson, Charis (2001) "Strategic Naturalizing: Kinship in Infertility Clinics". En Franklin, Sarah and McKinnon, Susan (eds.), Relative Values. Reconfiguring Kinship Studies. Durham and London: Duke University Press. 